University of Nebraska - Lincoln

DigitalCommons@University of Nebraska - Lincoln

$5-15-2008$

\title{
Modeling of thermodynamically coupled reaction-transport systems
}

Yasar Demirel

University of Nebraska Lincoln, ydemirel2@unl.edu

Follow this and additional works at: https://digitalcommons.unl.edu/cbmedemirel

Part of the Chemical Engineering Commons

Demirel, Yasar, "Modeling of thermodynamically coupled reaction-transport systems" (2008). Yasar Demirel Publications. 3.

https://digitalcommons.unl.edu/cbmedemirel/3

This Article is brought to you for free and open access by the Chemical and Biomolecular Research Papers -- Faculty Authors Series at DigitalCommons@University of Nebraska - Lincoln. It has been accepted for inclusion in Yasar Demirel Publications by an authorized administrator of DigitalCommons@University of Nebraska - Lincoln. 


\title{
Modeling of thermodynamically coupled reaction-transport systems
}

\author{
Yaşar Demirel \\ Department of Chemical and Biomolecular Engineering, University of Nebraska-Lincoln, \\ Lincoln, NE 68588, USA; tel 402 472-2745, fax 402 4720-6989, email ydemirel2@unl.edu
}

\begin{abstract}
Nonisothermal reaction-diffusion systems control the behavior of many transport and rate processes in physical, chemical and biological systems, such as pattern formation and chemical pumps. Considerable work has been published on mathematically coupled nonlinear differential equations by neglecting thermodynamic coupling between a chemical reaction and transport processes of mass and heat. This study presents the modeling of thermodynamically coupled system of a simple elementary chemical reaction with molecular heat and mass transport. The thermodynamic coupling refers that a flow occurs without or against its primary thermodynamic driving force, which may be a gradient of temperature or chemical potential or reaction affinity. The modeling is based on the linear nonequilibrium thermodynamics approach by assuming that the system is in the vicinity of global equilibrium. The modeling equations lead to unique definitions of cross-coefficients between a chemical reaction and heat and mass flows in terms of kinetic parameters, transport coefficients and degrees of coupling. These newly defined parameters need to be determined to describe some coupled reaction-transport systems. Some methodologies are suggested for the determination of the parameters and some representative numerical solutions for coupled reaction-transport systems are presented.
\end{abstract}

Keywords: balance equations, reaction-transport systems, thermodynamic coupling, nonequilibrium thermodynamics, degree of coupling

\section{Introduction}

Considerable work has been published on mathematically coupled nonlinear differential equations on reaction-diffusion systems in porous catalyst by neglecting the thermodynamic coupling. Here, the thermodynamic coupling refers that a flow (i.e. heat or mass flow or a reaction velocity) occurs without its primary thermodynamic driving force, or opposite to the direction imposed by its primary driving force. The principles of thermodynamics allow the progress of a process without or against its primary driving force only if it is coupled with another spontaneous process. This is consistent with the statement of second law, which states that a finite amount of organization may be obtained at the expense of a greater amount of disorganization in a series of coupled spontaneous processes.

Thermodynamically coupled chemical reaction-transport systems control the behavior of many transport and rate processes in physical, chemical and biological systems, and require a through analysis accounting the induced flows by cross-effects [1-13]. More than 50 years ago, Turing [1] demonstrated that a reaction-diffusion system with appropriate nonlinear kinetics can cause instability in a homogeneous steady state and generate stable concentration patterns. Also the energy coupling in the membranes of living cells plays major role in the respiratory electron transport chain leading to synthesizing adenosine triphosphate (ATP). The ATP synthesis in turn, is matched and synchronized to cellular ATP utilization $\mathrm{ADP}+P_{\mathrm{i}}+n \mathrm{H}_{\text {in }}^{+}=\mathrm{ATP}+\mathrm{H}_{2} \mathrm{O}+n \mathrm{H}_{\text {out }}^{+}$where "in" and "out" denote two phases separated by a membrane and $n$ is the ratio $\mathrm{H}^{+} / \mathrm{ATP}$, showing the level of transmembrane proton transport for each ATP to be synthesized [7]. Consequently, the hydrolysis of ATP is coupled to transporting substrates and maintaining the essential thermodynamic forces of ion electrochemical gradients [2-6]. For example, $\mathrm{Ca}^{2+}$-ATPase in the plasma membranes of most cells pump $\mathrm{Ca}^{2+}$ against a steep concentration gradient out of cytosol, while simultaneously counterport $\mathrm{H}^{+}$ions [5].

This study presents the modeling equations for thermodynamically and mathematically coupled system of a reversible elementary reaction with heat and mass flows. Such modeling may improve our understanding of some natural coupled processes, such as molecular pumps. The modeling is based on the linear nonequilibrium thermodynamics (LNET) formulations by assuming that the system is in the vicinity of global equilibrium (GE). Experimental investigations revealed that LNET is capable of describing thermodynamically coupled processes of 


\begin{tabular}{|c|c|c|c|}
\hline \multicolumn{2}{|c|}{ Nomenclature } & $x$ & ratio of forces \\
\hline \multirow{2}{*}{$\begin{array}{l}a_{1^{\prime}} a_{2} \\
A^{*}\end{array}$} & relations in Equation (10) & $X$ & thermodynamic force \\
\hline & nondimensional affinity in Equation (53) & $z$ & dimensionless distance \\
\hline$b$ & relation in Equation (50) $\left(\mathrm{mol} \mathrm{K} \mathrm{m}^{-2} \mathrm{~s}^{-1}\right)$ & \multirow{2}{*}{\multicolumn{2}{|c|}{ Greek letters }} \\
\hline C & concentration $\left(\mathrm{mol} \mathrm{m}^{-3}\right)$ & & \\
\hline$C_{\mathrm{Ss}_{\mathrm{s}}}$ & reactant concentration at surface $\left(\mathrm{mol} \mathrm{m}^{-3}\right)$ & $\Phi$ & volumetric entropy generation rate $\left(\mathrm{W} \mathrm{m}^{-3} \mathrm{~K}^{-1}\right)$ \\
\hline $\mathrm{Da}$ & Damköhler number & $\alpha_{\mathrm{e}}$ & effective thermal diffusivity $\left(\mathrm{m}^{2} \mathrm{~s}^{-1}\right)$ \\
\hline \multirow[t]{2}{*}{$D_{\mathrm{D}, \mathrm{e}}$} & coupling coefficient related to the Dufour effect & $\beta$ & thermicity group Equation (15), dimensionless \\
\hline & $\left(\mathrm{J} \mathrm{m}^{2} \mathrm{~mol}^{-1} \mathrm{~s}^{-1}\right)$ & $\varepsilon$ & dimensionless parameter related to Soret effect in \\
\hline \multirow[t]{2}{*}{$D_{\mathrm{S}, \mathrm{e}}$} & effective diffusion coefficient for the substrate $S$ & & Equation (52) \\
\hline & $\left(\mathrm{m}^{2} \mathrm{~s}^{-1}\right)$ & $r$ & Arrhenius group Equation (51) \\
\hline \multirow{2}{*}{$D_{\mathrm{T}, \mathrm{e}}$} & coupling coefficient related to the Soret effect & $\eta$ & effectiveness, efficiency \\
\hline & $\left(\mathrm{mol} \mathrm{m}^{-1} \mathrm{~s}^{-1} \mathrm{~K}^{-1}\right)$ & $\varphi$ & dimensionless temperature in Equation (15) \\
\hline E & activation energy of the chemical reaction $\left(\mathrm{J} \mathrm{mol}^{-1}\right)$ & $\kappa$ & dimensionless parameter in Equation (53) \\
\hline$\Delta H_{\mathrm{r}}$ & reaction enthalpy $\left(\mathrm{J} \mathrm{mol}^{-1}\right)$ & $\lambda_{\mathrm{S}}$ & relation in Equation (17) $\left(\mathrm{J} \mathrm{m}^{3} \mathrm{~mol}^{-2}\right)$ \\
\hline$J$ & diffusive mass flux (flow) $\left(\mathrm{mol} \mathrm{m}^{-2} \mathrm{~s}^{-1}\right)$ & $\mu$ & chemical potential \\
\hline$J_{\mathrm{a}}$ & conduction heat flux (flow) $\left(\mathrm{W} \mathrm{m}^{-2}\right)$ & $\theta$ & dimensionless concentration in Equation (10) \\
\hline$J_{r}^{\mathrm{q}}$ & volumetric reaction rate $\left(\mathrm{mol} \mathrm{m}^{-3} \mathrm{~s}^{-1}\right)$ & $\rho$ & density $\left(\mathrm{kg} \mathrm{m}^{-3}\right)$ \\
\hline$k_{\mathrm{e}}$ & effective thermal conductivity $\left(\mathrm{W} \mathrm{m}^{-1} \mathrm{~K}^{-1}\right)$ & $\sigma$ & dimensionless parameter in Equation (52) \\
\hline$k_{\mathrm{y}}^{\mathrm{e}}$ & first order reaction rate constant $\left(\mathrm{s}^{-1}\right)$ & $\tau$ & dimensionless time in Equation (51) \\
\hline$L^{\mathrm{v}}$ & characteristic half thickness $(\mathrm{m})$ & $\omega$ & dimensionless parameter related to Dufour effect \\
\hline Le & modified Lewis number & & in Equation (53) \\
\hline$L_{i k}$ & phenomenological coefficients & & \\
\hline \multirow[t]{2}{*}{$L_{\mathrm{qr}}$} & coupling coefficient between chemical reaction and & \multicolumn{2}{|c|}{ Subscripts } \\
\hline & heat flow $\left(\mathrm{mol} \mathrm{K} \mathrm{m} \mathrm{m}^{-2} \mathrm{~s}^{-1}\right)$ & $\mathrm{D}$ & Dufour \\
\hline \multirow[t]{2}{*}{$L_{\mathrm{Sr}}$} & coupling coefficient between chemical reaction and & e & effective \\
\hline & mass flow $\left(\mathrm{mol}^{2} \mathrm{~K} \mathrm{~J}^{-1} \mathrm{~m}^{-2} \mathrm{~s}^{-1}\right)$ & eq & equilibrium \\
\hline$n$ & number of components & $\mathrm{q}$ & heat \\
\hline$N_{\mathrm{r}}$ & number of independent reactions & $\mathrm{r}$ & reaction \\
\hline$t$ & time $\left(\mathrm{s}^{-1}\right)$ & $\mathrm{s}$ & surface \\
\hline$T$ & temperature $(\mathrm{K})$ & S & Soret \\
\hline $\mathrm{V}$ & total volume of membrane $\left(\mathrm{m}^{3}\right)$ & $\mathrm{T}$ & thermal diffusivity \\
\hline
\end{tabular}

oxidative phosphorylation, mitochondrial $\mathrm{H}^{+}$pumps and $\left(\mathrm{Na}^{+}\right.$ and $\mathrm{K}^{+}$)-ATPase, because mainly due to enzymatic feedback [2-5]. Moreover, the LNET formulation does not require the detailed mechanism of the coupling [4, 5, 15-18]. Kinetic descriptions and considerations may lead to a loss of the generality characteristics of thermodynamic formulations, since the kinetics is based on specific models [3]. The modeling equations have produced some unique parameters related to crosscoefficients between scalar process of chemical reaction and vectorial processes of heat and mass flows. These parameters combine the kinetic parameters, transport coefficients and degrees of thermodynamic coupling, and relate the cross-interactions to measurable quantities. Some representative solutions of coupled reaction-transport systems by Mathematica are presented.

\section{Background}

\subsection{Balance equations}

We consider a reversible homogeneous elementary reaction between a substrate $(\mathrm{S})$ and a product $(\mathrm{P}) \mathrm{S} \underset{k_{\mathrm{b}}}{\stackrel{k_{\mathrm{f}}}{\rightleftarrows}} \mathrm{P}$, where $k_{\mathrm{f}}$ and $k_{\mathrm{b}}$ are the forward and backward reaction rate constants, respectively. This type of reaction system is common in chemical and biological systems, such as unimolecular isomerization [17], enzyme kinetics [2] and racemization of molecules with mirror-image structures [18]. The well known balance equations are

$$
\begin{aligned}
& \frac{\partial C_{\mathrm{S}}}{\partial t}=-\nabla \mathbf{J}_{\mathrm{S}}+v_{\mathrm{S}} J_{\mathrm{r}} \\
& \frac{\partial C_{\mathrm{P}}}{\partial t}=-\nabla \mathbf{J}_{\mathrm{P}}+v_{\mathrm{P}} J_{\mathrm{r}} \\
& \rho c_{\mathrm{p}} \frac{\partial T}{\partial t}=-\nabla \mathbf{J}_{\mathrm{q}}+\left(-\Delta H_{\mathrm{r}}\right) J_{\mathrm{r}}
\end{aligned}
$$

where $\mathbf{J}_{\mathbf{q}}$ is the vector of reduced heat flow $\mathbf{J}_{\mathbf{q}}=\mathbf{q}-\sum_{i=1}^{n} \mathbf{J}_{i} H_{i^{\prime}}$ q the total heat flow, $H_{i}$ the partial molar enthalpy of species $i$ and $\Delta H_{\mathrm{r}}$ is the heat of reaction. The reaction velocity is $\mathrm{d} C_{\mathrm{S}} / \nu_{\mathrm{S}} \mathrm{d} t=\mathrm{d} C_{\mathrm{P}} / \nu_{\mathrm{P}} \mathrm{d} t=J_{\mathrm{r}}$ and the parameters $\nu_{\mathrm{S}}$ and $\nu_{\mathrm{P}}$ are the stoichiometric coefficients, which are negative for reactants $\left(v_{S}=-1\right)$. By using the Fick and Fourier laws in one-dimensional domain of $y$-direction and neglecting any thermo- 
dynamic coupling, Equations (1)-(3) become

$$
\begin{aligned}
& \frac{\partial C_{\mathrm{S}}}{\partial t}=D_{\mathrm{S}, \mathrm{e}} \frac{\partial^{2} C_{\mathrm{S}}}{\partial y^{2}}+\nu_{\mathrm{S}} J_{\mathrm{r}} \\
& \frac{\partial C_{\mathrm{P}}}{\partial t}=D_{\mathrm{P}, \mathrm{e}} \frac{\partial^{2} C_{\mathrm{P}}}{\partial y^{2}}+\nu_{\mathrm{P}} J_{\mathrm{r}} \\
& \rho c_{\mathrm{p}} \frac{\partial T}{\partial t}=k_{\mathrm{e}} \frac{\partial^{2} T}{\partial y^{2}}+\left(-\Delta H_{\mathrm{r}}\right) J_{\mathrm{r}}
\end{aligned}
$$

where $D_{i, \mathrm{e}}$ is the effective diffusivity for component $i$ and $k_{\mathrm{e}}$ is the effective thermal conductivity. For a simple slab geometry shown in Figure 1, the initial and boundary conditions are

$$
\begin{aligned}
& t=0: C_{\mathrm{S}}=C_{\mathrm{So}^{\prime}} C_{\mathrm{P}}=C_{\mathrm{Po}^{\prime}} T=T_{\mathrm{o}} \\
& y= \pm L: C_{\mathrm{S}}=C_{\mathrm{Ss}^{\prime}} C_{\mathrm{P}}=C_{\mathrm{Ps}^{\prime}} T=T_{\mathrm{S}} \quad \text { (surface conditions) } \\
& y=0: \partial C_{\mathrm{S}} / \partial y=\partial C_{\mathrm{P}} / \partial y=\partial T / \partial y \text { (symmetry conditions) }
\end{aligned}
$$

where $L$ is the half thickness of the slab. Diffusion may reduce averaged rates relative to that obtained if the concentration was everywhere $C_{\mathrm{Ss}}$. This limitation is quantified as the effectiveness factor $\eta$, and expressed as $\eta=(1 / V)\left(\int J_{\mathrm{r}}\left(C_{i}\right) \mathrm{d} V\right) / J_{\mathrm{r}}\left(C_{i \mathrm{~s}}\right)$, where $V$ is the volume [19].

At stationary state, eliminating the reaction terms from Equations (4) and (5), and integrating twice with the boundary conditions given above, concentrations of the species are related to each other by

$$
\theta_{\mathrm{P}}=a_{1}+a_{2}\left(1-\theta_{\mathrm{S}}\right)
$$

where

$$
\theta_{\mathrm{S}}=\frac{C_{\mathrm{S}}}{C_{\mathrm{Ss}}}, \quad \theta_{\mathrm{P}}=\frac{C_{\mathrm{P}}}{K C_{\mathrm{Ss}}}, \quad a_{1}=\frac{C_{\mathrm{Ps}}}{K C_{\mathrm{Ss}}}, \quad a_{2}=\frac{D_{\mathrm{S}, \mathrm{e}}}{K D_{\mathrm{P}, \mathrm{e}}}
$$

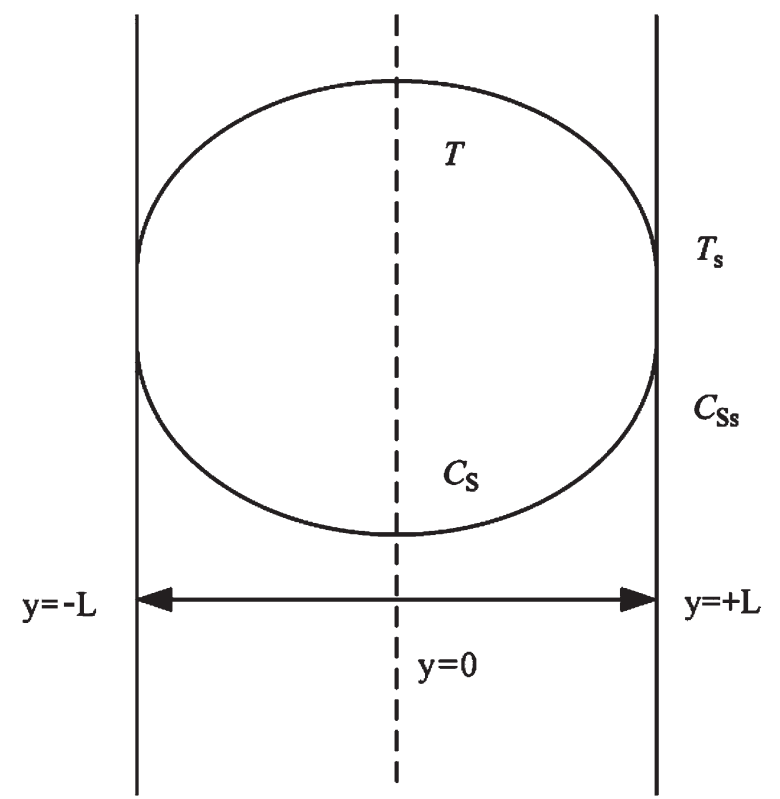

Figure 1. Schematic temperature and concentration profiles in a thin film. where $K$ is the chemical reaction equilibrium constant. The value of $a_{1}$ determines the direction of reaction; the net reaction is towards the $\mathrm{P}$ if $a_{1}<1$. After relating the two concentrations by Equation (10), at stationary state Equation (4) becomes

$$
\frac{\mathrm{d}^{2} \theta_{\mathrm{S}}}{\mathrm{d} z^{2}}=\left(D a_{\mathrm{S}}+D a_{\mathrm{P}}\right) \theta_{\mathrm{S}}-\left(D a_{\mathrm{S}} a_{1}+D a_{\mathrm{P}}\right)
$$

with the boundary conditions

$$
\theta_{\mathrm{S}}( \pm L)=1, \mathrm{~d} \theta_{\mathrm{S}}(0) / \mathrm{d} z=0
$$

where

$$
\begin{aligned}
& z=y / L \\
& D a_{\mathrm{S}}=k_{\mathrm{f}} L^{2} / D_{\mathrm{S}, \mathrm{e}} \quad D a_{\mathrm{P}}=k_{\mathrm{b}} L^{2} / D_{\mathrm{P}, \mathrm{e}}
\end{aligned}
$$

$D a_{\mathrm{S}}$ and $D a_{\mathrm{P}}$ are the Damköhler numbers and represent the ratios of the forward and backward reaction rates to the diffusion velocities $\left(D_{i, \mathrm{e}} / L\right)$. Therefore, they measure the intrinsic rates of the reactions relative to that of the diffusions, and represent an interaction between reaction and diffusion [20]. If the reaction is very fast, Damköhler number is large. For the product (P), an expression similar to Equation (11) can also be derived. Figure 2 displays the concentration profiles of the species of $S$ and $P$ at two different set of Damköhler numbers and $a_{1}=0.5$. When $D a_{\mathrm{S}}$ and $D a_{\mathrm{P}}$ are very large the concentrations of species $S$ and $P$ reach their equilibrium values within most of the film, and the approximate values of equilibrium concentrations become [20]

$$
\theta_{\mathrm{S}, \mathrm{eq}} \approx \theta_{\mathrm{P}, \mathrm{eq}} \approx \frac{a_{1}+\left(D a_{\mathrm{P}} / D a_{\mathrm{S}}\right)}{1+\left(D a_{\mathrm{P}} / D a_{\mathrm{S}}\right)}
$$

The relative diffusivities through the ratio of Damköhler numbers affect the equilibrium concentrations. Near the exposed surface $(z=0)$ the dimensional thickness of nonequilibrium region $\delta$ is proportional to the sum of the Damköhler numbers [20], and nondimensional nonequilibrium thickness $z^{\prime}$ is proportional to ratio of reaction rate and effective diffusiv-

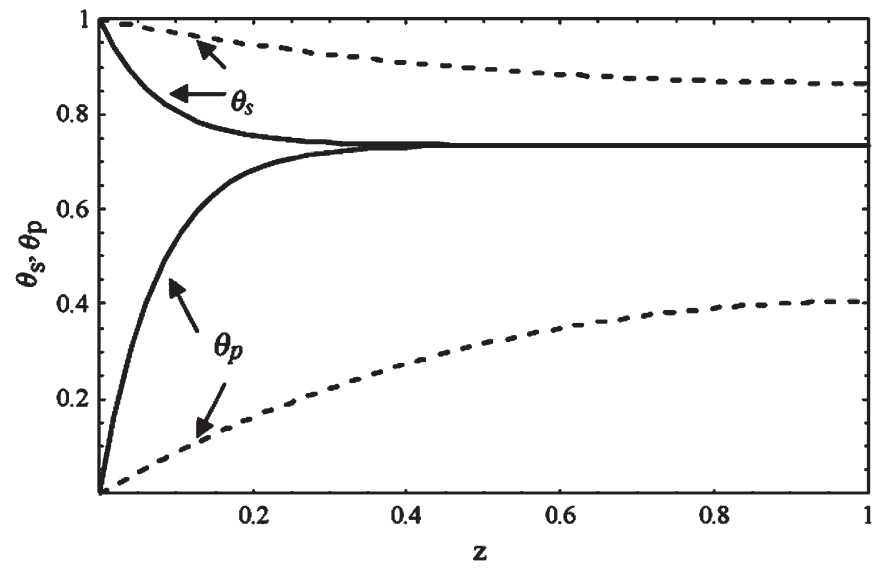

Figure 2. Concentration profiles for diffusion in a film with a reversible reaction. Bold line $D a_{\mathrm{S}}=90, D a_{\mathrm{P}}=80, a_{1}=0.5$. Dashed line $D a_{\mathrm{S}}=1.0, D a_{\mathrm{P}}=1.0, a_{1}=0.5$. 
ity and independent of the thickness $L$

$$
z^{\prime}=\frac{\delta}{L} \sim \frac{1}{\sqrt{D a_{\mathrm{S}}+D a_{\mathrm{P}}}} \sim \frac{1}{\sqrt{k / D_{\mathrm{e}}}}
$$

For large values of Damköhler numbers, the effectiveness becomes $\eta \sim 1 /(D a)^{1 / 2}[19]$.

By eliminating of the reaction terms from Equations (4) and (6) and integrating twice with the known boundary conditions, the temperature is related to the concentration by

$$
\varphi=1+\beta\left(1-\theta_{\mathrm{S}}\right)
$$

where

$$
\varphi=\frac{T}{T_{\mathrm{S}}}, \quad \beta=\frac{\left(-\Delta H_{\mathrm{r}}\right) D_{\mathrm{S}, \mathrm{e}} C_{\mathrm{Ss}}}{\left(-v_{\mathrm{S}}\right) k_{\mathrm{e}} T_{\mathrm{S}}}
$$

The value of $\beta$ is a measure of nonisothermal effects; as $\beta$ approaches zero, system becomes isothermal.

\subsection{Phenomenological equations}

Reaction-diffusion systems with heat effects represent open and nonequilibrium systems with thermodynamic forces of temperature gradient, concentration gradient and affinity. For the chemical reaction-transport system the local rate of entropy production is $[8,21]$

$$
\begin{aligned}
\Phi= & \mathbf{J}_{\mathrm{q}} \nabla\left(\frac{1}{T}\right)-\mathbf{J}_{\mathrm{S}} \frac{\left(\nabla \mu_{\mathrm{S}}\right)_{\mathrm{T}, \mathrm{P}}}{T} \\
& -\mathbf{J}_{\mathrm{P}} \frac{\left(\nabla \mu_{\mathrm{P}}\right)_{\mathrm{T}, \mathrm{P}}}{T}+J_{\mathrm{rS}} \frac{A}{T} \geq 0
\end{aligned}
$$

where $\left(\nabla \mu_{i}\right)_{\mathrm{T}, \mathrm{P}}=\sum_{\mathrm{i}=1}^{n-1}\left(\partial \mu_{i} / \partial C_{i}\right) \nabla C_{i}$. By using the GibbsDuhem equation at constant temperature and pressure $\left(C_{\mathrm{S}} \nabla \mu_{\mathrm{S}}+C_{\mathrm{P}} \nabla \mu_{\mathrm{P}}=0\right)$ and no volume flow condition $\left(\mathrm{J}_{\mathrm{S}}\right.$ $V_{\mathrm{S}}+\mathrm{J}_{\mathrm{P}} V_{\mathrm{P}}=0$ ), where $V_{i}$ is the partial molar volume of species $i$, Equation (16) becomes

$$
\Phi=-\mathbf{J}_{\mathrm{q}}\left(\frac{1}{T^{2}}\right) \nabla T-\mathbf{J}_{\mathrm{S}} \frac{1}{T} \lambda_{\mathrm{S}} \nabla C_{\mathrm{S}}+J_{\mathrm{rS}} \frac{A}{T} \geq 0
$$

where

$$
\lambda_{\mathrm{S}}=\left(1+\frac{C_{\mathrm{S}}}{C_{\mathrm{P}}}\right)\left(\frac{\partial \mu_{\mathrm{S}}}{\partial C_{\mathrm{S}}}\right)_{\mathrm{T}, \mathrm{P}}, \quad \text { for }\left(V_{\mathrm{S}} \approx V_{\mathrm{P}}\right)
$$

where $\mathbf{J}_{i}$ is the vector of mass flows, $\mu_{i}$ the chemical potential of species $i$ and $A$ is the affinity $\left(A=-\sum v_{i} \mu_{i}\right)$. Equation (17) consists of scalar processes of chemical reactions and vectorial processes of heat and mass flows, while it excludes viscous, electrical, and magnetic effects. Equation (17) identifies the following independent conjugate flows $J_{i}$ and forces $X_{k}$ to be used in the linear phenomenological equations (PEs) when the system is in the vicinity of GE

$$
\begin{aligned}
& \mathbf{J}_{\mathrm{S}}=-L_{\mathrm{SS}} \frac{1}{T} \lambda_{\mathrm{S}} \nabla C_{\mathrm{S}}-L_{\mathrm{Sq}} \frac{1}{T^{2}} \nabla T+\mathbf{L}_{\mathrm{Sr}} \frac{A}{T} \\
& \mathbf{J}_{\mathrm{q}}=-L_{\mathrm{qS}} \frac{1}{T} \lambda_{\mathrm{S}} \nabla C_{\mathrm{S}}-L_{\mathrm{qq}} \frac{1}{T^{2}} \nabla T+\mathbf{L}_{\mathrm{qr}} \frac{A}{T}
\end{aligned}
$$

$$
J_{\mathrm{r}}=-\mathbf{L}_{\mathrm{rS}} \frac{1}{T} \lambda_{\mathrm{S}} \nabla C_{\mathrm{S}}-\mathbf{L}_{\mathrm{rq}} \frac{1}{T^{2}} \nabla T+L_{\mathrm{rr}} \frac{A}{T}
$$

\subsection{The phenomenological coefficients}

The phenomenological coefficients $L_{i k}$ appearing above are related by various constraints, such as Onsager's reciprocity, Gibbs-Duhem equation at equilibrium, and the choice of reference frame for diffusivities. The type the constraints, on the other hand, depends on the choice of conjugate flows and forces, and frame of reference. Due to Onsager's reciprocal rules $\left(L_{i k}=L_{k i}\right)$ the number coefficients to be determined would be six instead of nine when the conjugate flows and forces are identified by a proper entropy generation relation and the flows are related to the forces linearly.

Onsager's reciprocal relations states that $L_{i k}=L_{k i}$ if $J_{i}$ and $J_{k}$ have the same parity under time reversal and $L_{i k}=-L_{k i}$ if $J_{i}$ and $J_{k}$ have the opposite parity. In the absence of pertinent symmetries or invariances, all types of cross-couplings are possible and lead to nonvanishing cross-coefficients $L_{i k}$. If the structure of the system is invariant with respect to some or all of the orthogonal transformations, then the invariance will eliminate certain cross-couplings and their cross-coefficients will vanish. If these symmetries are not exact then the corresponding cross-couplings would be weak and negligible. Of course the discussions above are valid only if the entropy production relation is properly derived using the correct and specific physics of a system considered [22].

For the nonvanishing cross-coefficients $L_{i k^{\prime}}$ all the forces contribute for each flow. Here, Equations (18)-(20) take into account the thermodynamic couplings between vectorial processes and between vectorial and scalar processes, which is possible in an anisotropic medium according to the Curie-Prigogine principle [15]. Curie-Prigogine principle states that "macroscopic causes always have fewer or equal symmetries than the effects they produce." Therefore, a scalar thermodynamic force such as chemical affinity, which has the high symmetry of isotropy, cannot cause a diffusion flow, which has lower symmetry because of its directionality. We can also state that a scalar cause cannot produce a vectorial effect, and generally, irreversible processes of different tensorial character (scalars, vectors and higher-order tensors) do not couple with each other. Therefore, the cross-coefficients $\mathbf{L}_{\mathrm{Sr}^{\prime}}, \mathbf{L}_{\mathrm{rS}}, \mathbf{L}_{\mathrm{qr}}$ and $\mathbf{L}_{\mathrm{rq}}$ would vanish in isotropic media (as commonly assumed) or would have vectorial character due to morphology of the interface, which separates reactants and products or due to compartmental structure causing an anisotropic character. For example, in active transport in biological cells, the hydrolysis of ATP is coupled with the flow of sodium ions outside of the cell. The flow direction is controlled by the structure of the membrane and coupling mechanisms in mitochondria. The medium may be locally isotropic, although it is not spatially homogenous. In this case, the coupling coefficients are associated with the whole system [2]. 


\subsection{The degrees of couplings}

The cross-coefficients determine the degrees of couplings between the pair of flows

$$
\begin{array}{ll}
r_{\mathrm{Sq}} & =\frac{L_{\mathrm{Sq}}}{\left(L_{\mathrm{SS}} L_{\mathrm{qq}}\right)^{1 / 2}}, \quad \mathbf{r}_{\mathrm{Sr}}=\frac{\mathbf{L}_{\mathrm{Sr}}}{\left(L_{\mathrm{SS}} L_{\mathrm{rr}}\right)^{1 / 2}}, \\
\mathbf{r}_{\mathrm{rq}} & =\frac{\mathbf{L}_{\mathrm{rq}}}{\left(L_{\mathrm{rr}} L_{\mathrm{qq}}\right)^{1 / 2}}
\end{array}
$$

Here, $r_{\mathrm{Sq}}$ is the degree of coupling between heat and mass flows, $\mathbf{r}_{\mathrm{Sr}}$ between chemical reaction and heat flow and $\mathbf{r}_{\mathrm{rq}}$ is between chemical reaction mass flow. The vectorial character of the degrees of couplings $\mathbf{r}_{\mathrm{Sr}}$ and $\mathbf{r}_{\mathrm{rq}}$ may reflect the morphological and/or compartmental structure of medium where couplings occur as well as the properties of the cross-coefficients $\mathbf{L}_{\mathrm{Sr}}$ and $\mathbf{L}_{\mathrm{rq}}[2,5,8,15,16,18]$.

\subsection{Determination of the coefficients}

The diagonal elements of the phenomenological coefficients $L_{i k}$ matrix $\mathbf{L}$ may be identified using the Fick, Fourier and the mass action laws. Comparison of the first term on the rhs of Equation (18) with Fick's law $\left(\mathbf{J}=-D_{\mathrm{S}, \mathrm{e}} \nabla C_{\mathrm{S}}\right)$ yields $L_{\mathrm{SS}}=D_{\mathrm{S}, \mathrm{e}} T / \lambda_{\mathrm{S}}$. Similarly, comparison of the second term on the rhs of Equation (19) with Fourier's law $\left(\mathbf{J}_{\mathrm{q}}=-k_{\mathrm{e}} \nabla T\right)$ yields $L_{\mathrm{qq}}=k_{\mathrm{e}} T^{2}$. The cross-coefficients $\left(L_{\mathrm{Sq}}\right.$ or $\left.L_{\mathrm{qS}}\right)$ may be represented by the Soret coefficient $\left(s_{\mathrm{T}}\right)$ or the thermal diffusion coefficient $\left(D_{\mathrm{T}}\right)$, which are related to each other by $L_{\mathrm{Sq}}=s_{\mathrm{T}} D_{\mathrm{S}, \mathrm{e}} T^{2} C_{\mathrm{S}}=D_{\mathrm{T}} T^{2} C_{\mathrm{S}}$. The Soret coefficient is the ratio of thermal diffusion coefficient to ordinary diffusion coefficient $\left(S_{\mathrm{T}}=D_{\mathrm{T}} / D_{\mathrm{S}, \mathrm{e}}\right)$ at steady state. The Soret coefficient changes in the range $10^{-2}$ to $10^{-3} \mathrm{~K}^{-1}$ for gases, nonelectrolytes and electrolytes, however it might be larger for polymer solutions $[18,23]$. The $L_{\mathrm{qS}}\left(=D_{\mathrm{T}} T^{2} C_{\mathrm{S}}\right)$ may be expressed by the Dufour coefficient $D_{\mathrm{D}} L_{\mathrm{qS}}=D_{\mathrm{D}} C_{\mathrm{S}} T / \lambda_{\mathrm{S}}$. For $L_{\mathrm{qS}}=L_{\mathrm{Sq}^{\prime}}$, we have $D_{\mathrm{D}}=D_{\mathrm{T}} T \lambda_{\mathrm{S}}$, which is proved experimentally [18]. For liquids, the diffusion coefficient $D$ is of the order of $10^{-5} \mathrm{~cm}^{2} \mathrm{~s}^{-1}$ and the thermal diffusion coefficient $D_{\mathrm{T}}$ is of the order of $10^{-8}$ to $10^{-10} \mathrm{~cm}^{2} \mathrm{~s}^{-1} \mathrm{~K}$. For gases, the order of magnitude for $D$ and $D_{\mathrm{T}}$ is $10^{-1} \mathrm{~cm}^{2} \mathrm{~s}^{-1}$ and $10^{-4}$ to $10^{-6} \mathrm{~cm}^{2} \mathrm{~s}^{-1} \mathrm{~K}$, respectively [18, 21, 24].

We may define two new effective diffusion coefficients of $\left(D_{\mathrm{T}, \mathrm{e}}\right.$ and $\left.D_{\mathrm{D}, \mathrm{e}}\right)$ that are related to the thermal diffusion and the Dufour effect, respectively

$$
\begin{aligned}
& D_{\mathrm{T}, \mathrm{e}}=L_{\mathrm{Sq}} \frac{1}{T^{2}}=s_{\mathrm{T}} D_{\mathrm{S}, \mathrm{e}} C_{\mathrm{S}}=D_{\mathrm{T}} C_{\mathrm{S}} \\
& D_{\mathrm{D}, \mathrm{e}}=L_{\mathrm{qS}} \frac{\lambda_{\mathrm{S}}}{T}=D_{\mathrm{D}} C_{\mathrm{S}}
\end{aligned}
$$

As the general transport equations are for an anisotropic medium to support the thermodynamic coupling between the scalar and the vectorial processes, the transport coefficients such as $k$ and $D$ become tensors of the second rank $\mathbf{\kappa}$ and $\mathbf{D}$ $[8,18,20]$. Here the effective transport coefficients incorporating the effects of the medium are taken into account for the simplicity.

\subsection{Reaction velocity}

The affinity for the reaction considered is $A=\mu_{\mathrm{S}}-\mu_{\mathrm{P}}$. The reaction velocity $J_{\mathrm{r}}$ in terms of affinity is $[8,16,18]$

$$
J_{\mathrm{r}}=J_{\mathrm{rf}}\left(1-\exp \left(-\frac{A}{R T}\right)\right)
$$

where $J_{\mathrm{rf}}=k_{\mathrm{f}} \mathrm{C}_{\mathrm{S}}$. If we expand Equation (24) at near GE state, which may be specified by the inequality $|A / R T| \ll 1$, then we have an approximate linear relationship between the reaction velocity and the chemical affinity for an elementary reaction

$$
J_{\mathrm{r}}=\frac{J_{\mathrm{rf}, \mathrm{eq}}}{R} \frac{A}{T}
$$

Thus, an elementary reaction rate is uniquely defined by the corresponding affinity since $J_{\text {rf,eq }}$ becomes constant due to uniform concentration at equilibrium when a system is in the vicinity of GE with fast diffusion and heat conduction processes. Comparing the third term on the right of Equation (20) with Equation (25), the coefficient $L_{\mathrm{rr}}$ is defined by

$$
L_{\mathrm{rr}}=\frac{J_{\mathrm{rf}, \mathrm{eq}}}{R}=\frac{k_{\mathrm{f}} C_{\mathrm{S}, \mathrm{eq}}}{R}=\frac{k_{\mathrm{o}} \exp \left(-E_{\mathrm{f}} / R T\right) C_{\mathrm{S}, \mathrm{eq}}}{R}
$$

where $k_{\mathrm{o}}$ is the frequency and $E_{\mathrm{f}}$ is the activation energy for the forward reaction. The $L_{\mathrm{rr}}$ is dependent on the rate constant and consequently on the equilibrium concentration $C_{\mathrm{S} \text {,eq }}$ and the amount of chemical catalyst.

Linear flow-force relations are valid when the Gibbs free energy ranges less than $1.5 \mathrm{~kJ} \mathrm{~mol}^{-1}$ for chemical reactions [15, 18]. However, some selected biological pathways occur at near GE conditions [2, 3], and for some chemical reactions, the formalism of LNET can be used in wider ranges than usually expected [14, 25-28]. By conservation of mass, some flow-force relations of enzyme catalyzed and other chemical reactions can be described by a simple hyperbolic-tangent function. Therefore, a plot of reaction velocity versus affinity has three regions; the regions at very high positive and negative values of affinity, the reaction velocity is almost independent of affinity. In between, however, the reaction velocity varies smoothly leading to a quasi-linear region around the inflection point. This region extends the linear flow-force relations over a $7 \mathrm{~kJ} \mathrm{~mol}^{-1}$ with an error in the reaction velocity less than $15 \%$. This behavior is independent of the reaction rate constants, and mainly occurs due to conservation conditions [27].

\subsection{The modified phenomenological equations}

With these newly defined primary and cross-coefficients, Equations (18)-(20) become

$$
\begin{aligned}
& \mathbf{J}_{\mathrm{S}}=-D_{\mathrm{S}, \mathrm{e}} \nabla C_{\mathrm{S}}-D_{\mathrm{T}, \mathrm{e}} \nabla T+\mathbf{L}_{\mathrm{Sr}} \frac{A}{T} \\
& \mathbf{J}_{\mathrm{q}}=-D_{\mathrm{D}, \mathrm{e}} \nabla C_{\mathrm{S}}-k_{\mathrm{e}} \nabla T+\mathbf{L}_{\mathrm{qr}} \frac{A}{T} \\
& J_{\mathrm{r}}=-\mathbf{L}_{\mathrm{rS}} \frac{1}{T} \lambda_{\mathrm{S}} \nabla C_{\mathrm{S}}-\mathbf{L}_{\mathrm{rq}} \frac{1}{T^{2}} \nabla T+\frac{k_{\mathrm{f}} C_{\mathrm{S}, \mathrm{eq}}}{R} \frac{A}{T}
\end{aligned}
$$


2.8. Determination of cross-coefficients for reaction-transport system

If we can control the temperature and concentration gradients, the coupling coefficients between the chemical reaction and the flows of mass and heat may be determined by the following relations

$$
\begin{aligned}
\mathbf{L}_{\mathrm{rS}} & =\mathbf{L}_{\mathrm{Sr}}=\left(\frac{\mathbf{J}_{\mathrm{S}}}{A / T}\right)_{\nabla C_{\mathrm{S}}=0, \nabla T=0} \cong\left(\frac{\Delta \mathbf{J}_{\mathrm{S}}}{\Delta(A / T)}\right)_{\nabla C_{\mathrm{S}}, \nabla T} \\
& =\left(\frac{\partial \mathbf{J}_{\mathrm{S}}}{\partial(A / T)}\right)_{\nabla C_{\mathrm{S}}, \nabla T} \cong\left(\frac{\mathbf{J}_{\mathrm{q}}}{A / T}\right)_{\nabla C_{\mathrm{S}}=0, \nabla T=0} \cong\left(\frac{\Delta \mathbf{J}_{\mathrm{q}}}{\Delta(A / T)}\right)_{\nabla C_{\mathrm{S}}, \nabla T} \\
\mathbf{L}_{\mathrm{rq}} & =\mathbf{L}_{\mathrm{qr}}=\left(\frac{\partial \mathbf{J}_{\mathrm{q}}}{\partial(A / T)}\right)_{\nabla C_{\mathrm{S}}, \nabla T} \cong
\end{aligned}
$$

For a closed system at stationary state $\mathbf{J}_{\mathrm{S}}=0$, we have

$$
\begin{aligned}
& \mathbf{J}_{\mathrm{S}}=0=-D_{\mathrm{S}, \mathrm{e}} \nabla C_{\mathrm{S}}-D_{\mathrm{T}, \mathrm{e}} \nabla T+\mathbf{L}_{\mathrm{Sr}} \frac{A}{T} \\
& \mathbf{L}_{\mathrm{Sr}}=\left(D_{\mathrm{S}, \mathrm{e}} \frac{\nabla C_{\mathrm{S}}}{A / T}+D_{\mathrm{T}, \mathrm{e}} \frac{\nabla T}{A / T}\right)=\mathbf{L}_{\mathrm{rS}}
\end{aligned}
$$

Using $A=R T \ln \left(J_{\mathrm{rf}} / J_{\mathrm{rb}}\right)$ in Equation (33), we get

$$
\mathbf{L}_{\mathrm{Sr}}=\frac{1}{R \ln \left(J_{\mathrm{rf}} / J_{\mathrm{rb}}\right)}\left(D_{\mathrm{S}, \mathrm{e}} \nabla C_{\mathrm{S}}+D_{\mathrm{T}, \mathrm{e}} \nabla T\right)=\mathbf{L}_{\mathrm{rS}}
$$

On the other hand, at chemical equilibrium, where $A=0$ and $J_{\mathrm{r}}=0$, we have

$$
J_{\mathrm{r}}=0=-\mathbf{L}_{\mathrm{rS}} \frac{1}{T} \lambda_{\mathrm{S}} \nabla C_{\mathrm{S}}-\mathbf{L}_{\mathrm{rq}} \frac{1}{T^{2}} \nabla T
$$

and the two coupling coefficients are related to each other by

$$
\mathbf{L}_{\mathrm{rq}}=-\mathbf{L}_{\mathrm{rS}} T \lambda_{\mathrm{S}} \frac{\nabla C_{\mathrm{S}}}{\nabla T}=\mathbf{L}_{\mathrm{qr}}
$$

By using the relationship $-C_{S} S_{T}=\nabla C_{S} / \nabla T$ at steady state, the coefficient $\mathbf{L}_{\mathrm{rq}}$ in terms of the Soret coefficient $s_{\mathrm{T}}$ becomes

$$
\mathbf{L}_{\mathrm{rq}}=\mathbf{L}_{\mathrm{rS}} T \lambda_{\mathrm{S}} C_{\mathrm{S}} S_{\mathrm{T}}
$$

Using Equation (34) in Equation (37), we find

$$
\mathbf{L}_{\mathrm{rq}}=\frac{T \lambda_{\mathrm{S}} C_{\mathrm{S}} s_{\mathrm{T}}}{A / T}\left[D_{\mathrm{S}, \mathrm{e}} \nabla C_{\mathrm{S}}+D_{\mathrm{T}, \mathrm{e}} \nabla T\right]
$$

Equations (34) and (38) suggest that the cross-coefficients $\mathbf{L}_{\mathrm{rq}}$ and $\mathbf{L}_{\mathrm{rS}}$ are related to the gradients of concentration and temperature, and control the induced effects between vectorial flows of heat and mass, and the scalar reaction velocity.

\section{Coupled system of chemical reaction and heat and mass flows}

By inserting Equations (27)-(29) into Equation (1) and Equation (3), we may describe the thermodynamically and mathematically coupled system of chemical reaction and heat and mass flows

$$
\begin{aligned}
\frac{\partial C_{\mathrm{S}}}{\partial t}= & -\nabla\left(-D_{\mathrm{S}, \mathrm{e}} \nabla C_{\mathrm{S}}-D_{\mathrm{T}, \mathrm{e}} \nabla T+\mathbf{L}_{\mathrm{Sr}} \frac{A}{T}\right) \\
& -\left(-\mathbf{L}_{\mathrm{rS}} \frac{\lambda_{\mathrm{S}}}{T} \nabla C_{\mathrm{S}}-\frac{\mathbf{L}_{\mathrm{rq}}}{T^{2}} \nabla T+\frac{k_{\mathrm{f}} C_{\mathrm{S}, \mathrm{eq}}}{R} \frac{A}{T}\right) \\
\rho c_{\mathrm{p}} \frac{\partial T}{\partial t}= & -\nabla\left(-D_{\mathrm{D}, \mathrm{e}} \nabla C_{\mathrm{S}}-k_{\mathrm{e}} \nabla T+\mathbf{L}_{\mathrm{qr}} \frac{A}{T}\right) \\
& +\left(-\Delta H_{\mathrm{r}}\right)\left(-\mathbf{L}_{\mathrm{rS}} \frac{\lambda_{\mathrm{S}}}{T} \nabla C_{\mathrm{S}}-\frac{\mathbf{L}_{\mathrm{rq}}}{T^{2}} \nabla T+\frac{k_{\mathrm{f}} C_{\mathrm{S}, \mathrm{eq}}}{R} \frac{A}{T}\right)
\end{aligned}
$$

Under mechanical equilibrium, we have

$$
\begin{aligned}
\nabla\left(\frac{\mu_{i}}{T}\right) & =\left[\mu_{i}-T\left(\frac{\partial \mu_{i}}{\partial T}\right)\right] \nabla\left(\frac{1}{T}\right)+\frac{\left(\nabla \mu_{i}\right)_{\mathrm{T}}}{T} \\
& =-H_{i} \frac{\nabla T}{T^{2}}+\frac{\left(\nabla \mu_{i}\right)_{\mathrm{T}}}{T}
\end{aligned}
$$

where $H_{i}$ is the partial enthalpy of species $i$. By using the definition of affinity $\left(A=\mu_{\mathrm{S}}-\mu_{\mathrm{P}}\right)$ and Equation (41) for the two components $\mathrm{S}$ and $\mathrm{P}$ with the Gibbs-Duhem equation $\left(C_{\mathrm{S}} \nabla \mu_{\mathrm{S}}+C_{\mathrm{P}} \nabla \mu_{\mathrm{P}}=0\right)$ and the following relations $\lambda_{\mathrm{S}}=\left(1+C_{\mathrm{S}} /\right.$ $\left.C_{\mathrm{P}}\right)\left(\partial \mu_{\mathrm{S}} / \partial C_{\mathrm{S}}\right)_{\mathrm{T}, \mathrm{P}}\left(\right.$ for $\left.V_{\mathrm{S}}=V_{\mathrm{P}}\right), \Delta G_{\mathrm{r}}^{\mathrm{o}}+T \Delta S_{\mathrm{r}}=\Delta H_{\mathrm{r}^{\prime}}$ we obtain

$$
\nabla\left(\frac{A}{T}\right)=\left(\nabla\left(\frac{\mu_{\mathrm{S}}}{T}\right)-\nabla\left(\frac{\mu_{\mathrm{P}}}{T}\right)\right)=\frac{\lambda_{\mathrm{S}}}{T} \nabla C_{\mathrm{S}}-\frac{-\Delta H_{\mathrm{r}}}{T^{2}} \nabla T
$$

Substituting Equation (42) in Equations (39) and (40), we have

$$
\begin{aligned}
\frac{\partial C_{\mathrm{S}}}{\partial t}= & D_{\mathrm{S}, \mathrm{e}} \nabla^{2} C_{\mathrm{S}}+D_{\mathrm{T}, \mathrm{e}} \nabla^{2} T+\frac{\mathbf{L}_{\mathrm{rq}}+\mathbf{L}_{\mathrm{Sr}}\left(-\Delta H_{\mathrm{r}}\right)}{T^{2}} \nabla T \\
& -\frac{k_{\mathrm{f}} C_{\mathrm{S}, \mathrm{eq}}}{R} \frac{A}{T}
\end{aligned}
$$

$$
\begin{aligned}
\rho c_{\mathrm{p}} \frac{\partial T}{\partial t}= & D_{\mathrm{D}, \mathrm{e}} \nabla^{2} C_{\mathrm{S}}+k_{\mathrm{e}} \nabla^{2} T-\frac{\lambda_{\mathrm{S}}\left[\left(-\Delta H_{\mathrm{r}}\right) \mathbf{L}_{\mathrm{rS}}+\mathbf{L}_{\mathrm{qr}}\right]}{T} \nabla C_{\mathrm{S}} \\
& +\frac{\left(-\Delta H_{\mathrm{r}}\right) k_{\mathrm{f}} C_{\mathrm{S}, \mathrm{eq}}}{R} \frac{A}{T}
\end{aligned}
$$

where the group $(A / R T)$ is the dimensionless affinity $A^{*}$ and may be expressed by

$$
A^{*}=\frac{A}{R T}=\ln K(T)+\ln \left(\frac{a_{\mathrm{S}}}{a_{\mathrm{P}}}\right)=\ln \left(\frac{k_{\mathrm{f}}}{k_{\mathrm{b}}}\right)+\ln \left(\frac{C_{\mathrm{S}}}{C_{\mathrm{P}}}\right)
$$

In Equation (45), the activities of $a_{\mathrm{S}}$ and $a_{\mathrm{P}}$ are assumed to be equal to concentrations $C_{\mathrm{S}}$ and $C_{\mathrm{P}}$, respectively, by neglecting the nonideality effects on the species. Using the Arrhenius equations, we have

$$
\ln \left(\frac{k_{\mathrm{f}}}{k_{\mathrm{b}}}\right)=\frac{E_{\mathrm{b}}-E_{\mathrm{f}}}{R T}
$$


Using Equation (46), we reduce Equations (43) and (44) to

$$
\begin{aligned}
\frac{\partial C_{\mathrm{S}}}{\partial t}= & D_{\mathrm{S}, \mathrm{e}} \nabla^{2} C_{\mathrm{S}}+D_{\mathrm{T}, \mathrm{e}} \nabla^{2} T+\frac{\mathbf{L}_{\mathrm{rq}}+\mathbf{L}_{\mathrm{Sr}}\left(-\Delta H_{\mathrm{r}}\right)}{T^{2}} \nabla T \\
& -\left[C_{\mathrm{S}, \text { eq }} k_{\mathrm{o}} \exp \left(\frac{-E_{\mathrm{f}}}{R T}\right)\right]\left(\frac{E_{\mathrm{b}}-E_{\mathrm{f}}}{R T}+\ln \left(\frac{C_{\mathrm{S}}}{C_{\mathrm{P}}}\right)\right)
\end{aligned}
$$

$$
\begin{aligned}
\rho c_{\mathrm{p}} \frac{\partial T}{\partial t}= & D_{\mathrm{D}, \mathrm{e}} \nabla^{2} C_{\mathrm{S}}+k_{\mathrm{e}} \nabla^{2} T-\frac{\lambda_{\mathrm{S}}\left[\left(-\Delta H_{\mathrm{r}}\right) \mathbf{L}_{\mathrm{rS}}+\mathbf{L}_{\mathrm{qr}}\right]}{T} \nabla C_{\mathrm{S}} \\
& +\left(-\Delta H_{\mathrm{r}}\right)\left[C_{\mathrm{S}, \operatorname{eq}} k_{\mathrm{o}} \exp \left(\frac{-E_{\mathrm{f}}}{R T}\right)\right] \\
& \times\left(\frac{E_{\mathrm{b}}-E_{\mathrm{f}}}{R T}+\ln \left(\frac{C_{\mathrm{S}}}{C_{\mathrm{P}}}\right)\right)
\end{aligned}
$$

One-dimensional forms of Equations (47) and (48) in the $y$-direction are

$$
\begin{aligned}
\frac{\partial C_{\mathrm{S}}}{\partial t}= & D_{\mathrm{S}, \mathrm{e}} \frac{\partial^{2} C_{\mathrm{S}}}{\partial y^{2}}+D_{\mathrm{T}, \mathrm{e}} \frac{\partial^{2} T}{\partial y^{2}}+\frac{b}{T^{2}} \frac{\partial T}{\partial y} \\
& -\left[C_{\mathrm{S}, \mathrm{eq}} k_{\mathrm{o}} \exp \left(\frac{-E_{\mathrm{f}}}{R T}\right)\right]\left(\frac{E_{\mathrm{b}}-E_{\mathrm{f}}}{R T}+\ln \left(\frac{C_{\mathrm{S}}}{C_{\mathrm{P}}}\right)\right)
\end{aligned}
$$

$$
\begin{aligned}
\frac{\partial T}{\partial t}= & \frac{D_{\mathrm{D}, \mathrm{e}}}{\rho c_{\mathrm{p}}} \frac{\partial^{2} C_{\mathrm{S}}}{\partial y^{2}}+\alpha_{\mathrm{e}} \frac{\partial^{2} T}{\partial y^{2}}-\frac{\lambda_{\mathrm{S}} b}{\rho c_{\mathrm{p}} T} \frac{\partial C_{\mathrm{S}}}{\partial y} \\
& +\frac{-\Delta H_{\mathrm{r}}}{\rho c_{\mathrm{p}}}\left[C_{\mathrm{S}, \mathrm{eq}} k_{\mathrm{o}} \exp \left(\frac{-E_{\mathrm{f}}}{R T}\right)\right] \\
& \times\left(\frac{E_{\mathrm{b}}-E_{\mathrm{f}}}{R T}+\ln \left(\frac{C_{\mathrm{S}}}{C_{\mathrm{P}}}\right)\right)
\end{aligned}
$$

where

$$
\begin{aligned}
b & =L_{\mathrm{rq}}+L_{\mathrm{Sr}}\left(-\Delta H_{\mathrm{r}}\right)=L_{\mathrm{rr}}\left[L_{\mathrm{qq}} r_{\mathrm{rq}}^{2}+L_{\mathrm{SS}} r_{\mathrm{Sr}}^{2}\left(-\Delta H_{\mathrm{r}}\right)\right] \\
& =\frac{k_{\mathrm{f}} C_{\mathrm{S}, \mathrm{eq}} T}{R}\left(k_{\mathrm{e}} T r_{\mathrm{rq}}^{2}+\left(\frac{D_{\mathrm{S}, \mathrm{e}}}{\lambda_{\mathrm{S}}}\right) r_{\mathrm{Sr}}^{2}\left(-\Delta H_{\mathrm{r}}\right)\right)
\end{aligned}
$$

Equations (49) and (50) use the same initial and boundary conditions given in Equations (7)-(9). With the following parameters

$$
\begin{array}{cc}
z=\frac{y}{L}, \quad \tau=\frac{D_{\mathrm{S}, \mathrm{e}} t}{L^{2}}, \quad D a_{\mathrm{S}}=\frac{L^{2} k_{\mathrm{o}} \exp \left(E_{\mathrm{f}} / R T_{\mathrm{S}}\right)}{D_{\mathrm{S}, \mathrm{e}}}, \\
\gamma_{\mathrm{f}}=\frac{E_{\mathrm{f}}}{R T_{\mathrm{S}}}, \quad \gamma_{\mathrm{b}}=\frac{E_{\mathrm{b}}}{R T_{\mathrm{S}}}, & L e=\frac{k_{\mathrm{e}} / \rho C_{\mathrm{p}}}{D_{\mathrm{S}, \mathrm{e}}}=\frac{\alpha_{\mathrm{e}}}{D_{\mathrm{S}, \mathrm{e}}}
\end{array}
$$

Nondimensional forms of Equations (49) and (50) become

$$
\begin{aligned}
\frac{\partial \theta_{\mathrm{S}}}{\partial \tau}= & \frac{\partial^{2} \theta_{\mathrm{S}}}{\partial z^{2}}+\varepsilon \frac{\partial^{2} \varphi}{\partial z^{2}}+\frac{\sigma}{\varphi^{2}} \frac{\partial \varphi}{\partial z} \\
& -A^{*} D a_{\mathrm{S}} \theta_{\mathrm{S}, \text { eq }} \exp \left[\gamma_{\mathrm{f}}\left(1-\frac{1}{\varphi}\right)\right]
\end{aligned}
$$

$$
\begin{aligned}
\frac{1}{L e} \frac{\partial \varphi}{\partial \tau}= & \frac{\partial^{2} \varphi}{\partial z^{2}}+\omega \frac{\partial^{2} \theta_{\mathrm{S}}}{\partial z^{2}}-\frac{\kappa}{\varphi} \frac{\partial \theta_{\mathrm{S}}}{\partial z} \\
& +A^{*} D a_{\mathrm{S}} \beta \theta_{\mathrm{S}, \text { eq }} \exp \left[\gamma_{\mathrm{f}}\left(1-\frac{1}{\varphi}\right)\right]
\end{aligned}
$$

where

$$
\begin{aligned}
& \varepsilon=\frac{D_{\mathrm{T}, \mathrm{e}} T_{\mathrm{S}}}{D_{\mathrm{S}, \mathrm{e}} C_{\mathrm{Ss}}}, \quad \omega=\frac{D_{\mathrm{D}, \mathrm{e}} c_{\mathrm{S}}}{k_{\mathrm{e}} T_{\mathrm{s}}}, \\
& \sigma=\frac{b L}{T_{\mathrm{s}} D_{\mathrm{S}, \mathrm{e}} C_{\mathrm{Ss}}}=\frac{\left[L_{\mathrm{rq}}+L_{\mathrm{Sr}}\left(-\Delta H_{\mathrm{r}}\right)\right] L}{T_{\mathrm{s}} D_{\mathrm{S}, \mathrm{e}} C_{\mathrm{Ss}}}, \quad \kappa=\frac{b C_{\mathrm{Ss}} L \lambda_{\mathrm{S}}}{k_{\mathrm{e}} T_{\mathrm{s}}^{2}}
\end{aligned}
$$

and

$$
A^{*}=\left(\frac{\gamma_{\mathrm{b}}-\gamma_{\mathrm{f}}}{\varphi}\right)+\ln \left(\frac{\theta_{\mathrm{S}}}{K\left[a_{1}+a_{2}\left(1-\theta_{\mathrm{S}}\right)\right]}\right)
$$

The parameter $b$ is defined in Equation (50). These equations suggest that the degree of couplings beside the other parameters would control the evolution and stability of the system. Therefore, induced effects due to various coupling phenomena can increase the possibility that the system may evolve to multiple states and diversify its behavior [27, 30]. The parameters $\varepsilon, \sigma, \omega$ and $\kappa$ above are associated with the cross-coefficients and hence control the coupled phenomena in the $y$-direction. Specifically, the $\varepsilon$ and $\omega$ control the coupling between mass and heat flows, while the $\sigma$ and $\kappa$ control the coupling between the chemical reaction and mass flow, and chemical reaction and heat flow, respectively. The initial and boundary conditions based on Equations (7)-(9) become

$$
\begin{array}{ll}
\tau=0: & \theta_{\mathrm{S}}=\theta_{\mathrm{So}}, \quad \theta_{\mathrm{P}}=\theta_{\mathrm{Po}}, \quad \varphi=\varphi_{\mathrm{o}} \\
z= \pm 1, \tau>0: & \theta_{\mathrm{S}}=1, \quad \theta_{\mathrm{P}}=1, \quad \varphi=1 \\
z=0, \tau>0: & \frac{\partial \theta_{\mathrm{S}}}{\partial z}=\frac{\partial \theta_{\mathrm{P}}}{\partial z}=\frac{\partial \varphi}{\partial z}=0
\end{array}
$$

Here, the nondimensional concentrations $\theta_{\mathrm{S}}$ and $\theta_{\mathrm{P}}$ are related approximately to each other by the relation $\theta_{\mathrm{P}}=a_{1}+a_{2}\left(1-\theta_{\mathrm{S}}\right)$, although it is derived for stationary states. Accuracy of the solutions obtained from Equations (52) and (53) depends on the reliable data, such as the effective transport coefficients and cross-coefficients. The parameter $b$ in terms of the degrees of couplings $r_{\mathrm{qr}}$ and $r_{\mathrm{Sr}}$ may improve the accuracy since the degrees of couplings vary between -1 and +1 . Some processes will not be dependent on some of the forces when some certain cross-coefficients vanish naturally. For example, some degrees of imperfections due to parallel pathways of reaction or intrinsic uncoupling within the pathway itself may lead to leaks and slips in mitochondria $[3,5]$.

\section{Some special cases of coupled phenomena}

Previously, we have considered the one-dimensional case where heat and mass flows are coupled in a reaction-diffusion system with heat effects, in which the cross-coefficients $L_{\mathrm{rq}}$ and $L_{\mathrm{qr}}$ as well as $L_{\mathrm{rS}}$ and $L_{\mathrm{Sr}}$ have vanished [21]. This means that the reaction velocity is coupled neither with the heat flow nor with the mass flow. Now we present the one-dimensional modeling for the following thermodynamically coupled systems: 
(1) Coupled phenomena at stationary state.

(2) No coupling exists between the heat flow and chemical reaction: $L_{\mathrm{rq}}=L_{\mathrm{qr}}=0$.

(3) No coupling exists between the mass flow and chemical reaction: $L_{\mathrm{rS}}=L_{\mathrm{Sr}}=0$.

In all the systems above, heat and mass flows are still thermodynamically coupled. The modeling equations for these processes are derived and discussed briefly in the following sections.

\subsection{Stationary coupling of chemical reactions with heat and mass} flows

Stationary forms of Equations (52) and (53) are

$$
\begin{aligned}
& 0=\frac{\partial^{2} \theta_{\mathrm{S}}}{\partial z^{2}}+\varepsilon \frac{\partial^{2} \varphi}{\partial z^{2}}+\frac{\sigma}{\varphi^{2}} \frac{\partial \varphi}{\partial z}-A^{*} D a_{\mathrm{S}} \theta_{\mathrm{S}, \text { eq }} \exp \left[\gamma\left(1-\frac{1}{\varphi}\right)\right] \\
& 0=\frac{\partial^{2} \varphi}{\partial z^{2}}+\omega \frac{\partial^{2} \theta_{\mathrm{S}}}{\partial z^{2}}-\frac{\kappa}{\varphi} \frac{\partial \theta_{\mathrm{S}}}{\partial z}+A^{*} D a_{\mathrm{S}} \beta \theta_{\mathrm{S}, \text { eq }} \exp \left[\gamma\left(1-\frac{1}{\varphi}\right)\right]
\end{aligned}
$$

The boundary conditions are defined in Equation (54). Using the previously derived relations $\varphi=1+\beta\left(1-\theta_{\mathrm{S}}\right)$ and $\theta_{\mathrm{P}}=a_{1}+a_{2}\left(1-\theta_{\mathrm{S}}\right)$ in Equation (55), the temperature $\varphi$ is related to the concentration $\theta_{\mathrm{S}}$ and the concentrations $\theta_{\mathrm{P}}$ and $\theta_{\mathrm{S}}$ are related to each other, and we have

$$
\begin{aligned}
0= & (1-\varepsilon \beta) \frac{\mathrm{d}^{2} \theta_{\mathrm{S}}}{\mathrm{d} z^{2}}-\frac{\sigma \beta}{\left[1+\beta\left(1-\theta_{\mathrm{S}}\right)\right]^{2}} \frac{\mathrm{d} \theta_{\mathrm{S}}}{\mathrm{d} z} \\
& -\left[\left(\frac{\gamma_{\mathrm{b}}-\gamma_{\mathrm{f}}}{1+\beta\left(1-\theta_{\mathrm{S}}\right)}\right)+\ln \frac{\theta_{\mathrm{S}}}{a_{1}+a_{2}\left(1-\theta_{\mathrm{S}}\right)}\right] D a_{\mathrm{S}} \theta_{\mathrm{S}, \text { eq }} \\
& \times \exp \left[\gamma\left(1-\frac{1}{1+\beta\left(1-\theta_{\mathrm{S}}\right)}\right)\right]
\end{aligned}
$$

where the products $\varepsilon \beta$ and $\beta \sigma$

$$
\begin{aligned}
& \beta \varepsilon=\frac{\left(-\Delta H_{\mathrm{r}}\right) D_{\mathrm{T}, \mathrm{e}}}{\left(-v_{\mathrm{S}}\right) k_{\mathrm{e}}}, \\
& \beta \sigma=\frac{\left(-\Delta H_{\mathrm{r}}\right) b L}{\left(-v_{\mathrm{S}}\right) k_{\mathrm{e}} T_{\mathrm{s}}^{2}}=\frac{\left(-\Delta H_{\mathrm{r}}\right)\left[L_{\mathrm{rq}}+L_{\mathrm{Sr}}\left(-\Delta H_{\mathrm{r}}\right)\right] L}{\left(-v_{\mathrm{S}}\right) k_{\mathrm{e}} T_{\mathrm{s}}^{2}}
\end{aligned}
$$

represent the cross-effects due to the thermodynamic coupling at steady state. Similarly, an equation can be derived for the temperature $\varphi$.

\subsection{Chemical reaction velocity coupled to mass flow: $L_{r q}=L_{q r}=0$}

This specific coupling may approximately represent the active transport in biological cells in which hydrolysis of ATP is coupled with the uphill transport of ions. Experimental investigation of biological energy coupling systems shows that LNET formulation is capable of describing mitochondrial $\mathrm{H}^{+}$ pumps [3] and helps understanding molecular slips and ion leaks of $\mathrm{Ca}^{2+}$ and $\mathrm{H}^{+}[5,7]$.

The following rate of entropy production equation shows the two contributions when there is no heat effect [2].

$$
\begin{aligned}
\Phi & =-\mathrm{J}_{\mathrm{S}}(1 / \mathrm{T}) \lambda_{\mathrm{S}} \nabla C_{\mathrm{S}}+J_{\mathrm{rS}}(\mathrm{A} / \mathrm{T})=\text { mass flow }+ \text { chemical reaction } \\
& =\text { output }+ \text { input } \geq 0
\end{aligned}
$$

For the active transport in a biological cell, the chemical reaction term $\left(J_{\mathrm{rS}}(A / T)\right)$ represents the hydrolysis of ATP, which facilitates pumping the ions opposite to the direction imposed by their thermodynamic forces, and hence we have $\left(-\mathrm{J}_{S}(1)\right.$ $\left.T) \lambda_{S} \nabla C_{S}\right)<0$. The efficiency of energy conversion for active transport may be related to the degree of coupling by using Equation (58)

$$
\eta=\frac{\text { output }}{\text { input }}=\frac{-\mathbf{J}_{\mathrm{S}}(1 / T) \lambda_{\mathrm{S}} \nabla C_{\mathrm{S}}}{J_{\mathrm{rS}}(A / T)}=\frac{x\left[\left(L_{\mathrm{SS}} / L_{\mathrm{rr}}\right)^{1 / 2} x+r_{\mathrm{Sr}}\right]}{r_{\mathrm{Sr}}+\left(L_{\mathrm{rr}} / L_{\mathrm{SS}}\right)^{1 / 2}}
$$

where $x$ is the ratio of thermodynamic forces $\left(\left[(1 / T) \lambda_{S} \nabla C_{S} /(A /\right.\right.$ $T)$ ]. The optimal efficiency would be a function of the degree of coupling [2-4, 13].

When the cross-coefficients $\mathbf{L}_{\mathrm{rq}}$ and $\mathbf{L}_{\mathrm{qr}}$ vanish in Equations (27), (28) and (29), the PEs become

$$
\begin{aligned}
& \mathbf{J}_{\mathrm{S}}=-D_{\mathrm{S}, \mathrm{e}} \nabla C_{\mathrm{S}}-D_{\mathrm{T}, \mathrm{e}} \nabla T+\mathbf{L}_{\mathrm{Sr}} \frac{A}{T} \\
& \mathbf{J}_{\mathrm{q}}=-D_{\mathrm{D}, \mathrm{e}} \nabla C_{\mathrm{S}}-k_{\mathrm{e}} \nabla T \\
& J_{\mathrm{r}}=-\mathbf{L}_{\mathrm{rS}} \frac{1}{T} \lambda_{\mathrm{S}} \nabla C_{\mathrm{S}}+\frac{k_{\mathrm{o}} \exp \left(-E_{\mathrm{f}} / R T\right) C_{\mathrm{S}, \mathrm{eq}}}{R} \frac{A}{T}
\end{aligned}
$$

so that the one-dimensional balance equations are

$$
\begin{gathered}
\frac{\partial \theta_{\mathrm{S}}}{\partial \tau}=\frac{\partial^{2} \theta_{\mathrm{S}}}{\partial z^{2}}+\varepsilon \frac{\partial^{2} \varphi}{\partial z^{2}}+\frac{\sigma^{\prime}}{\varphi^{2}} \frac{\partial \varphi}{\partial z} \\
-A^{*} D a_{\mathrm{S}} \theta_{\mathrm{S}, \text { eq }} \exp \left[\gamma\left(1-\frac{1}{\varphi}\right)\right] \\
\frac{1}{L e} \frac{\partial \varphi}{\partial \tau}=\frac{\partial^{2} \varphi}{\partial z^{2}}+\omega \frac{\partial^{2} \theta_{\mathrm{S}}}{\partial z^{2}}-\frac{\kappa^{\prime}}{\varphi} \frac{\partial \theta_{\mathrm{S}}}{\partial z} \\
+A^{*} D a_{\mathrm{S}} \beta \theta_{\mathrm{S}, \text { eq }} \exp \left[\gamma\left(1-\frac{1}{\varphi}\right)\right]
\end{gathered}
$$

where

$$
\sigma^{\prime}=\frac{\left[L_{\mathrm{Sr}}\left(-\Delta H_{\mathrm{r}}\right)\right] L}{T_{\mathrm{s}} D_{\mathrm{S}, \mathrm{e}} C_{\mathrm{Ss}}} ; \quad \kappa^{\prime}=\frac{\left[L_{\mathrm{Sr}}\left(-\Delta H_{\mathrm{r}}\right)\right] C_{\mathrm{Ss}} L \lambda_{\mathrm{S}}}{k_{\mathrm{e}} T_{\mathrm{s}}^{2}}
$$

By relating the cross-coefficient to the degree of coupling $r_{\mathrm{Sr}}$, the cross-coefficient $L_{\mathrm{Sr}}$ may be eliminated

$L_{\mathrm{Sr}}=r_{\mathrm{Sr}}\left(L_{\mathrm{SS}} L_{\mathrm{rr}}\right)^{1 / 2}=r_{\mathrm{Sr}}\left(\frac{D_{\mathrm{S}, \mathrm{e}} T}{\lambda_{\mathrm{S}}} \frac{k_{\mathrm{f}} C_{\mathrm{S}, \mathrm{eq}}}{R}\right)^{1 / 2}$ 


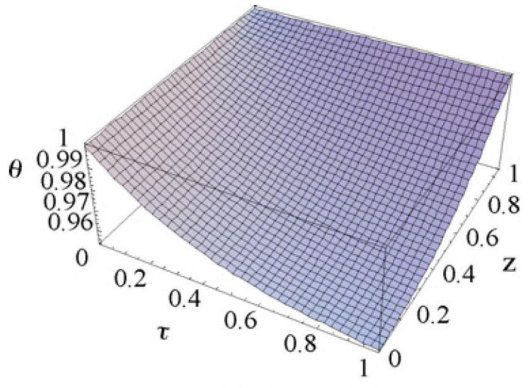

(a) $D a_{\mathrm{s}}=1.0$

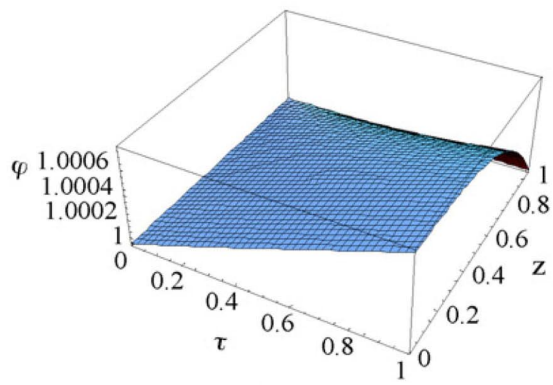

(b) $D a_{\mathrm{S}}=1.0$

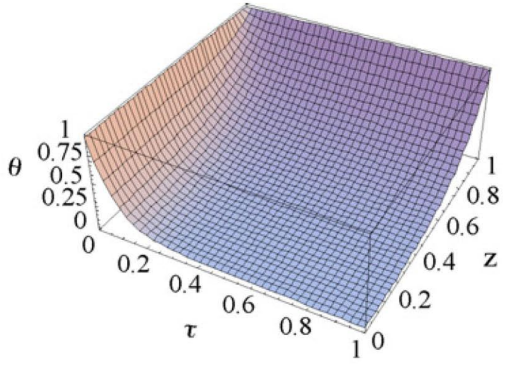

(a) $D a_{\mathrm{s}}=100.0$

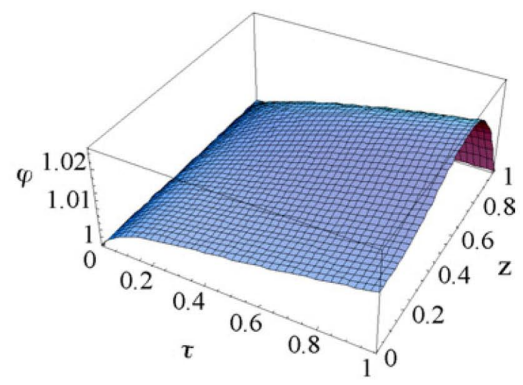

(b) $D a_{\mathrm{S}}=100.0$

Figure 3. Dimensionless temperature and concentration profiles obtained from Equations (62) and (63) with $\gamma=27, \beta=0.066, L e=0.11, \varepsilon=1.0$, $\omega=0.01, A^{*}=0.1, \sigma^{\prime}=0.1, \kappa^{\prime}=0.001$.

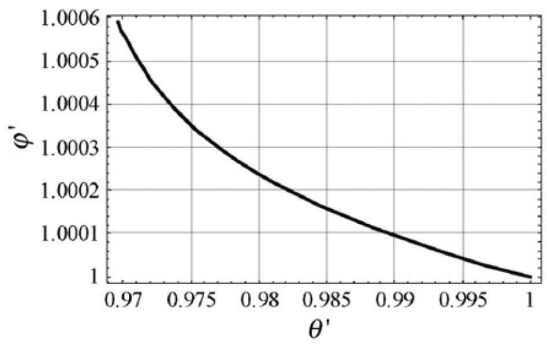

(a) $D a_{\mathrm{s}}=1.0$

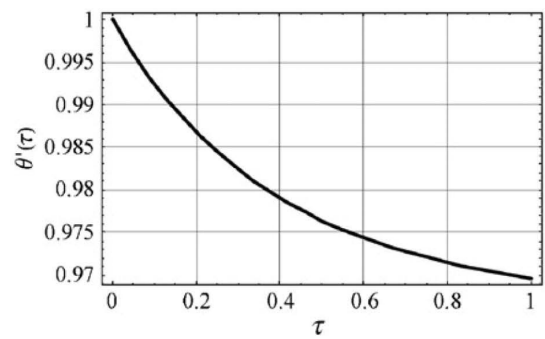

(b) $D a_{\mathrm{s}}=1.0$

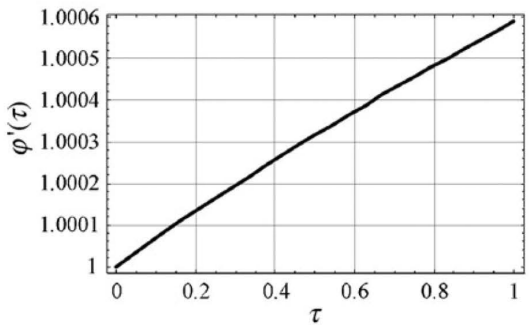

(c) $D a_{\mathrm{s}}=1.0$

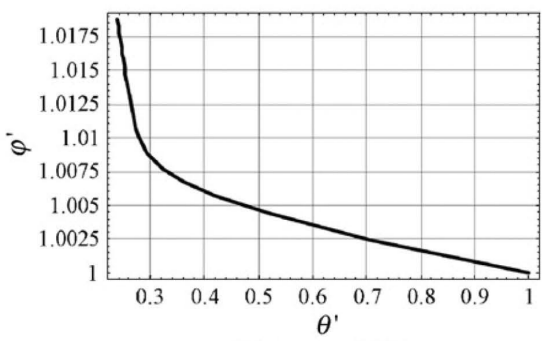

(a) $D a_{\mathrm{s}}=100.0$

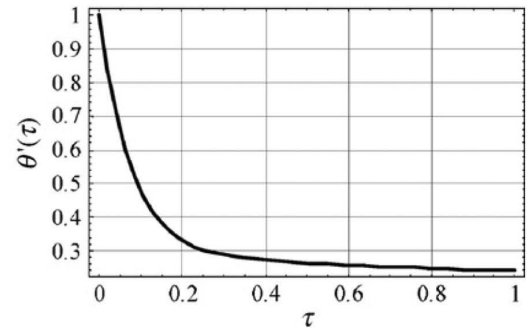

(b) $D a_{\mathrm{s}}=100.0$

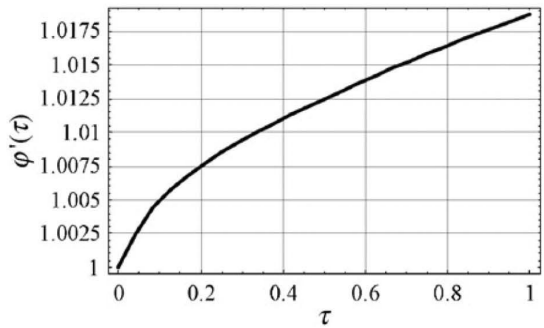

(c) $D a_{\mathrm{s}}=100.0$

Figure 4. Spatial integral averages obtained from Equations (66) and (67) using Equations (62) and (63): (a) change of temperature with concentration when the time varies between 0 and $1,(b)$ change of concentration with time and (c) change of temperature with time for $\gamma=27, \beta=0.066$, $L e=0.11, \varepsilon=1.0, \omega=0.01, A^{*}=0.1, \sigma^{\prime}=0.1, \mathrm{~K}^{\prime}=0.001$. 
and the parameters $\sigma^{\prime}$ and $\kappa^{\prime}$ are defined in terms of the degree of coupling $r_{\mathrm{Sr}}$

$$
\begin{aligned}
& \sigma^{\prime}=r_{\mathrm{Sr}}\left(\frac{D_{\mathrm{S}, \mathrm{e}} T}{\lambda_{\mathrm{s}}} \frac{k_{\mathrm{f}} C_{\mathrm{S}, \mathrm{eq}}}{R}\right)^{1 / 2} \frac{\left[\left(-\Delta H_{\mathrm{r}}\right)\right] L}{T_{\mathrm{S}} D_{\mathrm{S}, \mathrm{e}} C_{\mathrm{Ss}}} \\
& \kappa^{\prime}=r_{\mathrm{Sr}}\left(\frac{D_{\mathrm{S}, \mathrm{e}} T}{\lambda_{\mathrm{S}}} \frac{k_{\mathrm{f}} C_{\mathrm{S}, \mathrm{eq}}}{R}\right)^{1 / 2} \frac{\left(-\Delta H_{\mathrm{r}}\right) C_{\mathrm{Ss}} L \lambda_{\mathrm{S}}}{k_{\mathrm{e}} T_{\mathrm{s}}^{2}}
\end{aligned}
$$

The parameter $\kappa^{\prime}$ combines the forward reaction rate constant, diffusivity coefficient and thermal conductivity, and hence may reflect an "indirect interaction" between chemical reaction and heat flow with vanishing cross-coefficients of $L_{\mathrm{rq}}$ and $L_{\mathrm{qr}}$.

During a diffusion-controlled reaction, matter may be transported through an interface, which separates the reactants and the product. The progress of the reaction may be affected by the morphology of the interface with complicated structure, which controls the boundary conditions for the transport problem [27-29]. Morphological stability of interfaces in nonequilibrium systems may lead to self-organization and/or pattern-formation in biological, physical, chemical and geological systems [26, 29]. Turing [1] demonstrated that even some simple reaction-diffusion systems could lead to spatial organizations due to instability of stationary structure depending on the activator-inhibitor interactions, control parameters and boundary conditions (see Appendix A).

\subsubsection{Concentration and temperature profiles}

The Mathematica is used to solve the thermodynamically coupled systems of Equations (62) and (63) with the maximum steps of infinity. Figure 3 displays the dynamic behavior of the concentrations and temperatures at two different Damköhler numbers. For the fast reaction case with $D a_{\mathrm{S}}=100.0$, nonequilibrium region is considerably smaller and attained at a shorter time. For the slow reaction case with $D a_{\mathrm{S}}=1.0$, the system remains in nonequilibrium for most of the time and throughout the thickness of the film. The surfaces of temperature closely follow the change in concentrations, and reflect the effect of Damköhler numbers. As expectedly, the rise of temperature is small as the value of $\beta$ is relatively small.

Since the dynamic behavior of a reaction-transport system may be more apparent with the state-space diagrams, the temperature and concentration profiles are replaced with the spatial integral averages obtained from

$$
\begin{aligned}
& \theta^{\prime}(\tau)=\int_{0}^{1} \theta(z, \tau) \mathrm{d} z \\
& \varphi^{\prime}(\tau)=\int_{0}^{1} \varphi(z, \tau) \mathrm{d} z
\end{aligned}
$$

Figure $4 \mathrm{a}$ compares the state-space plots of temperature versus concentration when the time changes from zero to one. Figure $4 \mathrm{~b}$ and c shows the changes of the spatial integral averages of temperatures and concentrations. The spatial integral average of concentration reaches its equilibrium value approximately at $\tau=0.4$ at $D a_{\mathrm{S}}=100$. The changes are relatively sharp at $D a_{\mathrm{S}}=100.0$ while they are gradual at $D a_{\mathrm{S}}=1.0$, as expected. Figure 5 shows the spatial integral averages of temperatures and concentrations at $D a_{\mathrm{S}}=100$ with different values of coupling
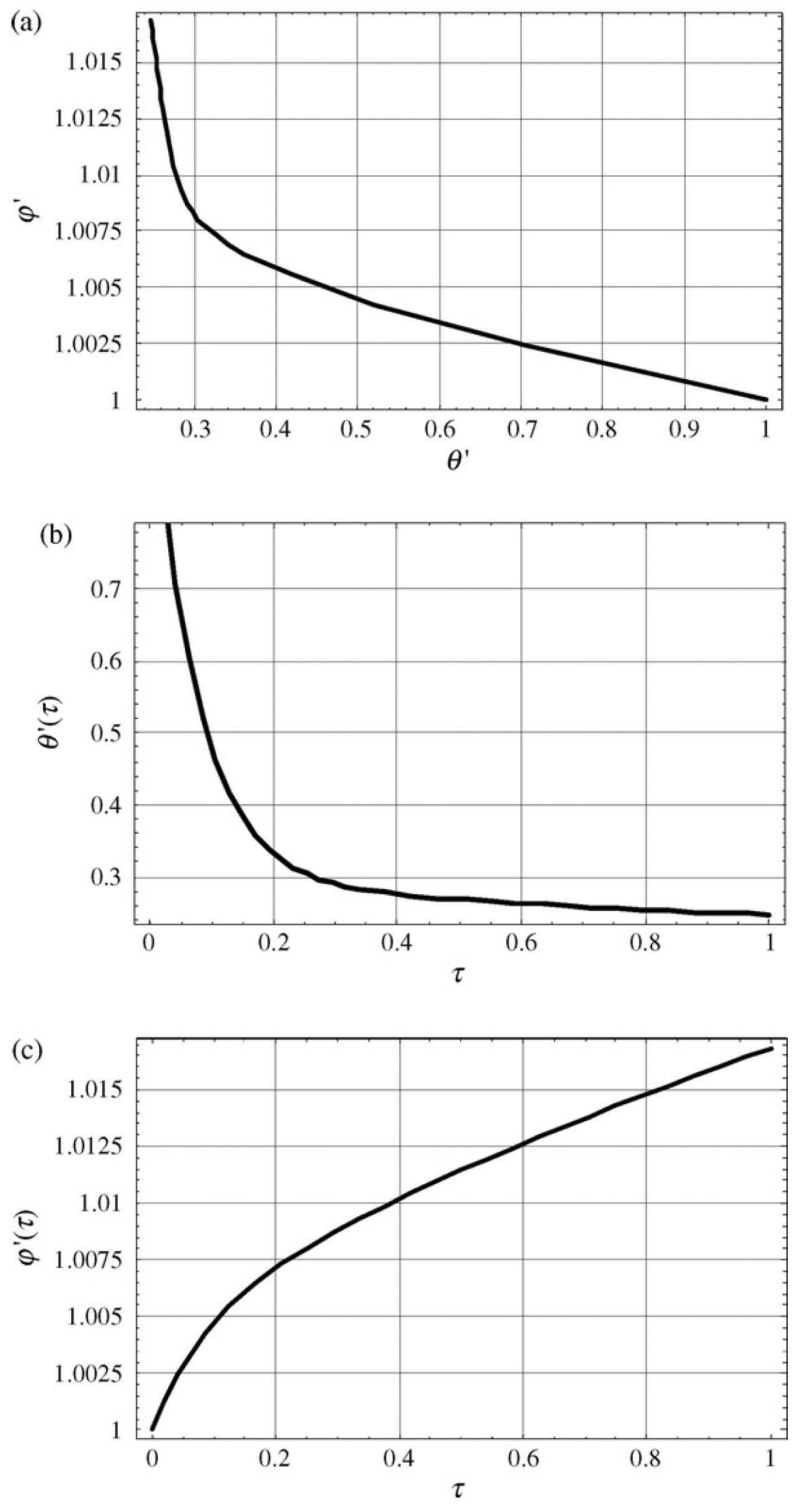

Figure 5. Spatial averages obtained by integrating Equations (62) and (63) with Equations (66) and (67): (a) change of temperature with concentration when the time varies between 0 and 1 , (b) change of concentration with time and (c) change of temperature with time for $D a_{\mathrm{S}}=100.0, \gamma=27 ; \beta=0.066 ; \mathrm{Le}=0.11, \varepsilon=1.0, \omega=0.001, A^{*}=0.1 ; \sigma$ ' $=0.001 ; \kappa^{\prime}=0.001$.

parameters. The marginal changes on the spatial integral averages of temperatures and concentrations may result from the coupling effects.

\subsection{Chemical reaction velocity coupled to heat flow: $L_{S r}=L_{r S}=0$}

The cross-coefficients $\mathbf{L}_{\mathrm{Sr}}$ and $\mathbf{L}_{\mathrm{rS}}$ vanish, and we have the following new PEs

$$
\begin{aligned}
& \mathbf{J}_{\mathrm{S}}=-D_{\mathrm{S}, \mathrm{e}} \nabla C_{\mathrm{S}}-D_{\mathrm{T}, \mathrm{e}} \nabla T \\
& \mathbf{J}_{\mathrm{q}}=D_{\mathrm{D}, \mathrm{e}} \nabla C_{\mathrm{S}}-k_{\mathrm{e}} \nabla T+\mathbf{L}_{\mathrm{qr}}(1 / T) A
\end{aligned}
$$




$$
J_{\mathrm{r}}=-\mathbf{L}_{\mathrm{rq}} \frac{1}{T^{2}} \nabla T+\frac{k_{\mathrm{o}} \exp \left(-E_{\mathrm{f}} / R T\right) C_{\mathrm{S}, \mathrm{eq}}}{R} \frac{A}{T}
$$

So that the one-dimensional balance equations become

$$
\begin{gathered}
\frac{\partial \theta_{\mathrm{S}}}{\partial \tau}=\frac{\partial^{2} \theta_{\mathrm{S}}}{\partial z^{2}}+\varepsilon \frac{\partial^{2} \varphi}{\partial z^{2}}+\frac{\sigma^{\prime \prime}}{\varphi^{2}} \frac{\partial \varphi}{\partial z} \\
-A^{*} D a_{\mathrm{S}} \theta_{\mathrm{S}, \text { eq }} \exp \left[\gamma\left(1-\frac{1}{\varphi}\right)\right] \\
\frac{1}{L e} \frac{\partial \varphi}{\partial \tau}=\frac{\partial^{2} \varphi}{\partial z^{2}}+\omega \frac{\partial^{2} \theta_{\mathrm{S}}}{\partial z^{2}}-\frac{\kappa^{\prime \prime}}{\varphi} \frac{\partial \theta_{\mathrm{S}}}{\partial z} \\
+A^{*} D a_{\mathrm{S}} \beta \theta_{\mathrm{S}, \mathrm{eq}} \exp \left[\gamma\left(1-\frac{1}{\varphi}\right)\right]
\end{gathered}
$$

where

$$
\sigma^{\prime \prime}=\frac{L_{\mathrm{qr}} L}{T_{\mathrm{s}} D_{\mathrm{S}, \mathrm{e}} C_{\mathrm{Ss}}}, \quad \kappa^{\prime \prime}=\frac{L_{\mathrm{qr}} C_{\mathrm{Ss}} L \lambda_{\mathrm{S}}}{k_{\mathrm{e}} T_{\mathrm{s}}^{2}}
$$

By relating the parameters $\sigma^{\prime \prime}$ and $\kappa^{\prime \prime}$ and the cross-coefficient to the degree of coupling $r_{\mathrm{qr}}$, we have

$$
\begin{aligned}
& L_{\mathrm{qr}}=r_{\mathrm{qr}}\left(L_{\mathrm{qq}} L_{\mathrm{rr}}\right)^{1 / 2}=r_{\mathrm{qr}}\left(k_{\mathrm{e}} T^{2} \frac{k_{\mathrm{f}} C_{\mathrm{S}, \mathrm{eq}}}{R}\right)^{1 / 2} \\
& \sigma^{\prime \prime}=r_{\mathrm{qr}}\left(k_{\mathrm{e}} T^{2} \frac{k_{\mathrm{f}} C_{\mathrm{S}, \mathrm{eq}}}{R}\right)^{1 / 2} \frac{L}{T_{\mathrm{s}} D_{\mathrm{S}, \mathrm{e}} C_{\mathrm{Ss}}} \\
& \kappa^{\prime \prime}=r_{\mathrm{qr}}\left(k_{\mathrm{e}} T^{2} \frac{k_{\mathrm{f}} C_{\mathrm{S}, \mathrm{eq}}}{R}\right)^{1 / 2} \frac{C_{\mathrm{Ss}} L \lambda_{\mathrm{S}}}{k_{\mathrm{e}} T_{\mathrm{s}}^{2}}
\end{aligned}
$$

The parameter $\sigma^{\prime \prime}$ combines the transport and rate coefficient of $k_{\mathrm{e}^{\prime}} D_{\mathrm{S}, \mathrm{e}^{\prime}}$ and $k_{\mathrm{f}}$.

\section{Conclusions}

The balance equations are derived for thermodynamically and mathematically coupled system of chemical reaction and heat and mass flows. This effort may be a starting point to understand the molecular coupled phenomena between vectorial and scalar processes, such as active transport in biological cells. These modeling equations are based on the linear nonequilibrium thermodynamics approach assuming that the system is in the vicinity of global equilibrium and has anisotropic character. The equations have revealed definitions of some unique parameters related to the cross-coefficients between the scalar process of chemical reaction and the vectorial processes of heat and mass flows. These parameters combine kinetic parameters, transport coefficients, and degrees of thermodynamic couplings leading to a path for determinations of these parameters by some measurable quantities. The representative solutions of the modeling equations for the coupled chemical reaction-mass flow system are in line with the behavior of fast and slow chemical reactions in a film.
Acknowledgment - The constructive discussion with J. V. Sengers is greatly appreciated.

\section{Appendix A.}

If we consider the change of affinity with time at constant temperature and pressure, we have

$$
\frac{\mathrm{d} A}{\mathrm{~d} t}=\left(\frac{\partial A}{\partial C_{\mathrm{S}}}\right)_{\mathrm{T}, \mathrm{P}} \frac{\mathrm{d} C_{\mathrm{S}}}{\mathrm{d} t}
$$

It is possible to split the $\mathrm{d} C_{\mathrm{S}}$ into two parts: $\mathrm{d} C_{\mathrm{S}}=d_{\mathrm{e}} C_{\mathrm{S}}+d_{i} C_{\mathrm{S}^{\prime}}$ which are the part resulting from the exchange with the surrounding and the part due to a chemical reaction. The rate of the second part is the reaction velocity $d_{i} C_{S} / \mathrm{d} t=v_{\mathrm{S}} J_{\mathrm{r}}$. With these relations Equation (1) yields

$$
\frac{\mathrm{d} A}{\mathrm{~d} t}=\left(\frac{\partial A}{\partial C_{\mathrm{S}}}\right)_{\mathrm{T}, \mathrm{P}} \frac{d_{\mathrm{e}} C_{\mathrm{S}}}{\mathrm{d} t}-J_{\mathrm{rS}}\left(\frac{\partial A}{\partial C_{\mathrm{S}}}\right)_{\mathrm{T}, \mathrm{P}}
$$

Equation (2) shows that affinity changes by rate of supply of matter and chemical reaction velocity. Depending on the rate of supply, the first term in Equation (2) may counter balance the reaction velocity, so that the affinity may become a constant. This new phenomenon represents as system where one of the forces is fixed, and may lead to a specific behavior in the evolution of the whole system $[2,16]$.

Evolution equation, in general, is expressed by

$$
\partial \mathbf{Y} / \partial t=f(\mathbf{Y}, \lambda)
$$

where $\mathbf{Y}$ is the column vector with the elements of the state variables $Y_{1}, \ldots, Y_{i}$, which are continuously subjected to either internal fluctuations or external perturbations. The $f$ is mainly a nonlinear space operator and $\lambda$ denotes a set of controlling parameters affecting the evolution, such as thermal conductivity, diffusivity, chemical rate constants and initial concentrations of reactants and products. The evolution equations for the dimensionless concentration $\theta_{\mathrm{S}}$ and the temperature $\varphi$ in the form of Equation (3) become

$$
\begin{aligned}
\frac{\partial C_{\mathrm{S}}}{\partial t}= & f_{\mathrm{S}}\left[C_{\mathrm{Ss}}, C_{\mathrm{Ps}}, T_{\mathrm{s}}, \lambda\left(\tau, D_{\mathrm{S}, \mathrm{e}}, D_{\mathrm{P}, \mathrm{e}}, D_{\mathrm{T}, \mathrm{e}}, \varepsilon, \sigma, \gamma_{\mathrm{f}}, A^{*},\right.\right. \\
& \left.\left.\phi_{\mathrm{Ss}}, \theta_{\mathrm{S}, \mathrm{eq}}, r_{\mathrm{Sq}}, r_{\mathrm{rq}}, r_{\mathrm{Sr}}\right)\right] \\
\frac{\partial T}{\partial t}= & f_{\mathrm{T}}\left[C_{\mathrm{Ss}}, C_{\mathrm{Ps}}, T_{\mathrm{s}}, \lambda\left(\tau, \alpha_{\mathrm{e}}, \beta, D_{\mathrm{S}, \mathrm{e}}, \omega, \kappa, \gamma_{\mathrm{f}}, \gamma_{\mathrm{b}}, A^{*},\right.\right. \\
& \left.\left.\theta_{\mathrm{S}, \mathrm{eq}}, r_{\mathrm{Sq}}, \mathbf{r}_{\mathrm{rq}}, \mathbf{r}_{\mathrm{Sr}},-\Delta H_{\mathrm{r}}, L e\right)\right]
\end{aligned}
$$

As Equations (4) and (5) suggest, the degree of couplings beside the other parameters would control the evolution and stability of the system. Comparison of Equation (4) with the simple rate expression of $\mathrm{d} C_{\mathrm{S}} / \mathrm{d} t=-k_{\mathrm{f}} \mathrm{C}_{\mathrm{S}}+k_{\mathrm{b}} \mathrm{C}_{\mathrm{p}}$ alone displays the expansion in the number of controlling parameters in the coupled system of an elementary reaction with heat and mass flows. Therefore, induced cross-effects due to various coupling phenomena can allow the system to evolve to multiple solutions and diversify its behavior depending on many controlling parameters $[25,29]$. 


\section{References}

[1] A. M. Turing, The chemical basis of morphogenesis, Philos. Trans. R. Soc. Lond. B 237 (1952), pp. 37-72.

[2] R. S. Caplan and A. Essig, Bioenergetics and Linear Nonequilibrium Thermodynamics. The Steady State (Reprint), Harvard University Press, New York (1999).

[3] J. W. Stucki, M. Compiani, and S. R. Caplan, Efficiency of energy conversion in model biological pumps optimization by linear nonequilibrium thermodynamic relations, Biophys. Chem. 18 (1983), pp. 101-109.

[4] Y. Demirel and S. I. Sandler, Thermodynamics of bioenergetics, Biophys. Chem. 97 (2002), pp. 87-111.

[5] A. R. Waldeck, K. van Dam, J. Berden, and P. W. Kuchel, A nonequilibrium thermodynamics model of reconstituted $\mathrm{Ca}^{2+}$ ATPase, Eur. Biophys. J. 27 (1998), pp. 255-262.

[6] Y. Demirel and S. I. Sandler, Effects of concentration and temperature on the coupled heat and mass transport in liquid mixtures, Int. J. Heat Mass Transfer 45 (2002), pp. 75-86.

[7] P. Turina, D. Samurai, and P. Graber, $\mathrm{H}^{+} /$ATP ratio of proton transport-coupled ATP synthesis and hydrolysis catalyzed by CF0F1 \pm liposomes, Eur. Mol. Biol. Org. J. 22 (2003), pp. 418-426.

[8] Y. Demirel, Non-equilibrium Thermodynamics: Transport and Rate Processes in Physical and Biological Systems, Elsevier, Amsterdam (2002).

[9] Q. Jin and C. M. Bethke, Kinetics of electron transfer through the respiratory chain, Biophys. J. 83 (2002), pp. 1797-1808.

[10] R. Heinrich and S. Schuster, The modeling of metabolic systems. Structure, control and optimality, BioSystems 47 (1998), pp. 61-77.

[11] A. Burghardt and M. Berezowski, Periodic solutions in a porous catalyst pellet-homoclinic orbits, Chem. Eng. Sci. 58 (2003), pp. 2657-2670.

[12] P. Gas, C. Girardeaux, D. Mangelinck, and A. Portavoce, Reaction and diffusion at interfaces of micro- and nanostructured materials, Mater. Sci. Eng. B 101 (2003), pp. 43-48.

[13] Y. Demirel and S. I. Sandler, Nonequilibrium thermodynamics in engineering and science, J. Phys. Chem. B 108 (2004), pp. 31-43.

[14] D. Reguera, J. M. Rubi and J. M. G. Vilar, The mesoscopic dynamics of thermodynamic systems, J. Phys. Chem. B 109 (2005), pp. 21502-21515.
[15] I. Prigogine, Introduction to Thermodynamics of Irreversible Processes (3rd ed.), Wiley, New York (1967).

[16] S. R. De Groot, Thermodynamics of Irreversible Processes, North Holland, Amsterdam (1966).

[17] H. Qian and D. A. Beard, Thermodynamics of stoichiometric biochemical networks in living systems far from equilibrium, Biophys. Chem. 114 (2005), pp. 213-220.

[18] D. Kondepudi and I. Prigogine, Modern Thermodynamics; From Heat Engines to Dissipative Structures, Wiley, New York (1999).

[19] F. G. Froment and K. B. Bischoff, Chemical Reactor Analysis and Design, Wiley, New York (1979).

[20] W. M. Deen, Analysis of Transport Phenomena, Oxford University Press, New York (1998).

[21] Y. Demirel, Non-isothermal reaction diffusion system with thermodynamically coupled heat and mass transfer, Chem. Eng. Sci. 61 (2006), pp. 3379-3385.

[22] M. A. Lomholt, P. L. Hansen, and L. Miao, A general theory of nonequilibrium dynamics of lipid-protein fluid membranes, Eur. Phys. J. E 16 (2005), pp. 439-461.

[23] Y. Demirel and S.I. Sandler, Linear non-equilibrium thermodynamics theory for coupled heat and mass transport, Int. J. Heat Mass Transfer 44 (2001), pp. 2439-2451.

[24] J. Jost, Diffusion in Solids, Liquids and Gases, Academic Press, New York (1960).

[25] A. S. Cukrowski and A. Kolbus, On validity of linear phenomenological nonequilibrium thermodynamics equations in chemical kinetics, Acta Phys. Pol. B 36 (2005), pp. 1485-1507.

[26] Y. Demirel, Stability of transport and rate processes, Int. J. Thermodyn. 8 (2005), pp. 1-14.

[27] H. V. Westerhoff and K. van Dam, Thermodynamics and Control of Biological Free-energy Transduction, Elsevier, Amsterdam (1987).

[28] O. Aono, Thermodynamic coupling of diffusion with chemical reaction, J. Stat. Phys. 13 (1975), pp. 331-335.

[29] M. Martin, Materials in thermodynamic potential gradients, J. Chem. Thermodyn. 35 (2003), pp. 1291-1308.

[30] M. Ruszkowski, V. Garcia-Osorio, and E. Ydstie, Passivity based control of transport reaction systems, AIChE J. 51 (2005), pp. 3147-3166. 